\title{
Relative share, frequency and correlation of restorations in both dental dentitions in childhood
}

\author{
Dobrinka Damyanova, Radosveta Andreeva-Borisova \\ Department of Pediatric Dental Medicine, Faculty of Dental Medicine, Medical University of Varna, Bulgaria
}

\begin{tabular}{|c|c|}
\hline Article Info & ABSTRACT \\
\hline Article history: & \multirow{16}{*}{$\begin{array}{l}\text { This research aimed to analyze of the relative share, frequency and } \\
\text { correlation of restorations in both dental dentitions in childhood. The } \\
\text { decayed, missing, and filled permanent teeth (DMFT) index is one of the } \\
\text { most commonly used indices in epidemiologic surveys of dental caries. It } \\
\text { quantifies dental health status based on the number of carious, missing and } \\
\text { filled teeth. A total of } 602 \text { schoolchildren in Varna, aged } 3-18 \text { years were } \\
\text { selected for this study. The children have a determined high caries risk } \\
\text { DMFT index }>1 \text {. The patients are divided into } 16 \text { groups according to age } \\
\text { limit. The research takes place in the Faculty of Dental Medicine, Medical } \\
\text { University of Varna, in the time period 2016-2018. This study is } \\
\text { retrospective, based on medical data of the participants. Pearson's correlation } \\
\text { and simple linear regression were used to estimate the correlation between } \\
\text { restorations, DMF (T+t) and age. The average value of determining the level } \\
\text { of caries of the examined groups of children is DMF (T+t) }=5.46 \pm 3.95 \text { (range } \\
0-20 \text { ). With the correlation analysis we proved a direct dependence of the } \\
\text { ratio. The number of preventive fillings with photopolymers and composites } \\
\text { increased with increasing age of the studied children }(\mathrm{r}=0.725 \text {; p } 0.001 \text { ). } \\
\text { Their high distribution among the studied patients was established by } \\
\text { determining the average frequency of carious lesions. The correlation } \\
\text { analysis determined that with increasing age of the patients the number and } \\
\text { frequency of composite restorations and sealants in the control groups } \\
\text { increased. }\end{array}$} \\
\hline Received Oct 23, 2020 & \\
\hline Revised Jan 19, 2021 & \\
\hline Accepted Mar 10, 2021 & \\
\hline Keywords: & \\
\hline & \\
\hline $\begin{array}{l}\text { Dental carres } \\
\text { DMF index }\end{array}$ & \\
\hline & \\
\hline Fillings & \\
\hline Public health & \\
\hline Restoration & \\
\hline & \\
\hline & \\
\hline & \\
\hline & \\
\hline & \\
\hline
\end{tabular}

This is an open access article under the CC BY-SA license.

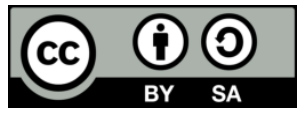

\section{Corresponding Author: \\ Dobrinka Damyanova \\ Department of Pediatric Dental Medicine, Faculty of Dental Medicine \\ Medical University of Varna \\ 84, Tsar Osvoboditel, 9000 Varna, Bulgaria \\ Email: dr_damyanova@abv.bg}

\section{INTRODUCTION}

The correlation between tooth decay, the relative share, frequency and restorations in both dental dentitions in childhood has not been researched or proven. The decayed, missing, and filled permanent teeth (DMFT) index is one of the most commonly used indices in epidemiologic surveys of dental caries. It quantifies dental health status based on the number of carious (D), missing (M) and filled teeth (T- for permanent teeth and t- for primary teeth). The minimally invasive restorative treatment of dental caries and its complications in primary teeth includes prolonged intervention and preparation of a cavity with a small size, limited to removing only the carious lesion [1]. Soon, it is expected for restorative materials to undergo complete change, because composite materials completely substitute amalgam fillings for restoration of cavities in primary teeth [2]. 
The commission of American Academy of Pediatric Dentistry (AAPD) accepts a guide for restorative dentistry in 1991 [3]. The last full revision of this consensus was in 2014. There have been 35 meta-analyses between 1995 and 2013, supporting this guide, which include systematic check-ups and 62 controlled clinical tests. The assessment of each of the topics is based on the new additions to the AAPD classification. Recommendations have been added: strong evidence (based on the partial control studies, meta-analyses and systematic reviews); evidence of clinical studies; expert opinions (based on retrospective studies, case reports, in vitro studies and opinions of clinical examiners) [4]. It has been proven that partial excavation of carious structures followed by placement of a final filling predetermines better results in maintaining the viability of the pulp in permanent teeth [5].

Glass-ionomer cements have been used in dental medicine as a restorative material since the beginning of 1970. The improvement of the content of the conventional glass-ionomer cements leads to better qualities, along with the modified with resin glass-ionomers. These restorative materials show an improvement in the work process, reduced time, needed for mixture, increased durability and improved sustainability. All glass-ionomers have qualities that make them favorable to use in primary teeth, including the chemical bond towards the enamel and dentin; temperature extension, such as that of dental structures; biocompatibility; releasing of fluoride and decreased sensitivity towards moisture, compared with resins.

The fluoride released from the glass-ionomer cements is intercepted from the area of the adjacent enamel and dentin, which leads to better resilience of the teeth towards acidic exposition [3]. Only one of the studies shows that the release of fluoride can occur for one year minimum. There is conclusive evidence, that the modified with resin glass-ionomers are efficient in the restoration of class I cavities. This expert opinion is sustained for class II cavities and their restorations in primary teeth [6], [7].

Compomers are polyacid-modified composites based on resin, and they make their appearance in dentistry in the $90 \mathrm{~s}$. The material consists of $72 \%$ strontium fluorsilicate glass and the size of the particles is 2.5 micrometers [8]. Most of the studies show that compomers have a tendency of improved physical qualities compared to glass-ionomers (and resin-modified glass-ionomers) for restorations of primary teeth. There has not been an established difference in the cariostatic effect of the compomers compared to the other obturation materials [9]-[11]. Compomers may be a choice instead of other restorative materials for primary dentition for class I and II cavities [12], [13]. Class III cavities or aproximal restorations of primary incisors are often prepared with a labial or lingual access, to include a bigger surface for better adhesion and improving the longevity of the restorations [14]. Cavities and fillings in the cervix region from class $\mathrm{V}$ of primary incisors are similar to the ones in permanent dentition [3].

If the patients are in an established high caries risk, restorations can be performed by using a crown [15]-[18]. A retrospective study shows that $80 \%$ of the teeth are completely preserved up until three years after the placement of preformed crowns and $20 \%$ were partially preserved, not a single primary tooth was missing [19]. Other retrospective study with duration 24-74 months has $80 \%$ success rate in restorations with preformed crowns [20].

Composite is the restorative material of choice [3], [21]. Bisphenol A (Methyl methacrylate) and its containers are resin components, included in sealants and composites. There is substantial evidence from a meta-analysis of 59 clinical studies of composite fillings in class I and II, which show $90 \%$ success rate after 10 years with experimental conditions [22]. Past controlled studies, comparing composite restorations with amalgam also show success. These studies show that a reason for the lack of success in these restorations is the recidive caries [23]-[26]. There is convincing evidence that composite fillings for class I in primary teeth are successful [27], [28]. Only one study showed success in restorations of class II, filled with composite. In primary teeth restorations it is important to take into account that the tooth is going to exfoliate in an interval of two years [29]. In permanent molars composites are recommended [30]. Concerning the different types of composites (hybrid, nano, macro and micro particles) there are results, showing the similarities in their clinical efficiency.

The recommendations of the commission of AAPD for composite materials are as follows: For primary molars there are controlled studies, which include composite resins successfully when they are used in class I restorations. For class II lesions of primary teeth there is one controlled study showing success in restorations with composites for two years. In permanent molars there are meta-analyses, showing that composite materials can be successfully used for class I and II restorations. The conclusions of the metaanalyses show that the adhesive materials towards the enamel and dentin decrease the marginal discoloration and visually "define" the borders of the different composite materials.

Sealants for deep fissures. Fissure caries of the occlusal surface is $80 \%$ to $90 \%$ of all caries in permanent teeth and $44 \%$ in primary molars [28]. Sealants are described as a material, placed in deep fissures and pits in caries predisposed teeth. They are connected micromechanically (with micro retentions after etching) which aims to prevent the access of cariogenic bacteria and their food source, thus decreasing the risk of caries development [30]. The evidence of their efficiency is achieved after a survey of Cochrane. The

Int. J. Public Health Sci., Vol. 10, No. 2, June 2021: 241 - 248 
sealants placed in the clinic on the occlusal fissure of the permanent molar teeth in children and adolescents lead to a reduction of caries up to 48 years [31]. According to the meta-analysis of 24 studies the efficiency of the autopolymerised sealants leads to a prevention of caries up to $71 \%$. Studies for their repeated placement show a success rate of $80 \%$ to $90 \%$ for 10 or more years [32], [33]. For the use of sealants for the prevention of dental caries in fissures of primary teeth, we have not found more published articles to support these successes [34]. One study shows $76.5 \%$ success in sealants on primary teeth for two years and eight months follow up [35].

\section{RESEARCH METHOD}

The research aimed to analysis of the relative share, frequency and correlation of restorations in both dental dentitions in childhood.

\subsection{Clinical methods and design of the research}

The subject of observation were children $(n=602)$ with primary, mixed or permanent dentition, who had treatment with restorative fillings in a total of 602 patients. The minimal age of the children is equal to three and the maximum age is 18 years. The patients live in Varna, Bulgaria and are chosen at random, based on high caries risk and active caries lesions, determined by caries risk assessment. The children have a determined high caries risk DMFT $(\mathrm{t})>1$. The materials we applied are the following: resin-modified glassionomer cement (Riva Light Cure Glass Ionomer Cement, compomers Dyract ${ }^{\mathrm{R}}$ (DeTrey GmbH Germany), light curing nano-hybrid composite for fillings [36]. In order to achieve techniques and results for preventive treatment and prevention, we placed sealants on the non-carious pit and fissures [37]. Criteria for including the children: clinically healthy, without systemic diseases, without pathology of the oral mucosa. Place and period of conduct. The study was conducted in the Faculty of dental medicine, Medical university of Varna, in the time period 2016-2018. This study is retrospective, based on medical data of the participants and it researches the frequency, relative share and correlation of restorations of irreversible and cavitated caries lesions with or without pulp inflammation, diagnosed as $\mathrm{d} 3, \mathrm{~d} 4$ lesions of primary and permanent teeth. The examiners are specialists in pediatric dentistry. The patients are divided into 16 groups according to age limit. In order for the research to be precise for every patient a caries index DMF $(T+t)$ has been determined. Carious (d), extracted due to caries (m) and filled (f) teeth are registered. When defining the caries index, non-cavitated lesions d1b are also included. Oral status is documented using an epidemiological dental health assessment card. All patients have received a declaration of consent for checkup and treatment, signed by their parents. The epidemiological chart includes a passport section, dental status, registration of the level of oral hygiene, evaluation of the risk of caries and analysis of the diagnostically established caries lesions. Units of observation are primary and permanent teeth, with or without caries lesions, active caries lesions diagnosed as d1b. Means of observation are carious, filled or missing tooth due to caries. Examined indicators are DMFT, DMF $(\mathrm{T}+\mathrm{t})$. Dmf consists of $\mathrm{d}+\mathrm{m}+\mathrm{f}$. The study calculates according to tooth. The value of the index is calculated for $/ \mathrm{d} 1, \mathrm{~d} 2 /$ and $/ \mathrm{d} 3, \mathrm{~d} 4 /$.

\subsection{Statistical methods and analysis}

Description analysis-the quantity distribution of the examined features, divided into groups, the average and standard deviation, 95\% interval of change in the average value are describes in charts. Dispersion analysis (ANOVA) -The purpose of this analysis is to establish the presence or absence of influence of two or more factors on the average number value of the examined indicators. The limit was chosen as $\mathrm{p}=0.05$. This is a chance to create an error of first degree, to dismiss the zero hypothesis. Regression analysis of Pearson-it aims to achieve a precise statistical model, describing the dependency of the values of count, frequency and type of the different restoration in child age depending on different variables such as age and caries risk of the children, frequency of caries and caries index of evaluation of the level of tooth decay. Correlative analysis employed for examining the dependency and coefficients between variables. Graphic and chart method of visualization of the data. Biostatistical method of analysis with mathematical and statistical package (SPSS) v 20.0 was applied.

\subsection{Statement of ethics}

The research is authorized by the Ethics Committee of the Scientific Research at the Medical University of Varna, Bulgaria and received informed consent from each parent, respectively, for each childpatient. 


\section{RESULTS AND DISCUSSION}

The average value of determining the level of caries of the examined groups of children is DMF $(\mathrm{T}+\mathrm{t})=5.46 \pm 3.95$ (range 0-20). This can be seen in Table 1 (95\% interval of change in the average value are describes in charts).

For preventive treatment and prevention, we placed sealants on the non-carious pit and fissures. The relative shares of the frequency of the sealants placed by us on the examined patients are shown with the results in more detail in Table 2. More ever, Table 3 shows that a direct ratio dependency, showing that with age increase, there is an increase in the count of places sealants $(r=0.646 \mathrm{p}<0.001)$.

Table 1. Distribution of caries index DMF $(\mathrm{T}+\mathrm{t})$ according to age of the examined children

Descriptives

\begin{tabular}{ccccccccc}
$\begin{array}{c}\text { DMFT } \\
\text { Age }\end{array}$ & $\mathrm{n}$ & Mean & Std. deviation & Std. error & $\begin{array}{c}\text { 95\% Confidence interval for mean } \\
\text { Lower bound }\end{array}$ & Upper bound & Minimum & Maximum \\
\hline 3.00 & 30 & 5.5000 & 3.10450 & .56680 & 4.3408 & 6.6592 & 1.00 & 13.00 \\
4.00 & 38 & 5.4737 & 4.02517 & .65297 & 4.1506 & 6.7967 & .00 & 14.00 \\
5.00 & 75 & 5.0800 & 3.67151 & .42395 & 4.2353 & 5.9247 & .00 & 15.00 \\
6.00 & 90 & 5.6222 & 4.22294 & .44514 & 4.7377 & 6.5067 & .00 & 20.00 \\
7.00 & 39 & 5.4872 & 3.30766 & .52965 & 4.4150 & 6.5594 & .00 & 12.00 \\
8.00 & 30 & 5.4333 & 3.91886 & .71548 & 3.9700 & 6.8967 & .00 & 14.00 \\
9.00 & 30 & 4.7667 & 3.47090 & .63370 & 3.4706 & 6.0627 & .00 & 11.00 \\
10.00 & 30 & 5.8333 & 4.33974 & .79232 & 4.2128 & 7.4538 & .00 & 14.00 \\
11.00 & 30 & 4.7333 & 4.35441 & .79500 & 3.1074 & 6.3593 & .00 & 17.00 \\
12.00 & 30 & 4.2000 & 2.98733 & .54541 & 3.0845 & 5.3155 & .00 & 15.00 \\
13.00 & 30 & 5.1000 & 3.74488 & .68372 & 3.7016 & 6.4984 & .00 & 14.00 \\
14.00 & 30 & 3.9000 & 3.47751 & .63490 & 2.6015 & 5.1985 & .00 & 15.00 \\
15.00 & 31 & 5.6452 & 3.70179 & .66486 & 4.2873 & 7.0030 & .00 & 15.00 \\
16.00 & 29 & 7.0000 & 5.53560 & 1.02793 & 4.8944 & 9.1056 & .00 & 17.00 \\
17.00 & 30 & 6.5000 & 3.80336 & .69439 & 5.0798 & 7.9202 & .00 & 13.00 \\
18.00 & 30 & 7.4000 & 4.33590 & .79162 & 5.7809 & 9.0191 & .00 & 16.00 \\
Total & 602 & 5.4618 & 3.95642 & .16125 & 5.1451 & 5.7785 & .00 & 20.00 \\
\hline
\end{tabular}

$\mathrm{F}=1.678, \mathrm{p}<0.05 ; *$ Statistically significant $(\mathrm{p}<0.05)$.

Table 2. Relative share of the frequency of placed sealants of the examined patients

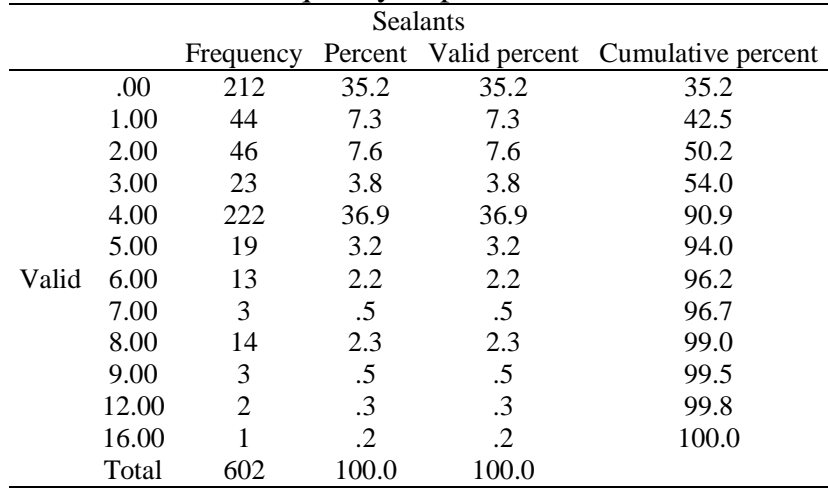

Table 3. Correlation analysis of Pearson for the dependency of the placed sealants and the age of the examined patients

\begin{tabular}{|c|c|c|c|c|}
\hline \multicolumn{5}{|c|}{ Symmetric measures } \\
\hline Correlation analysis & Value & Asymp. Std. error ${ }^{a}$ & Approx. $\mathrm{T}^{\mathrm{b}}$ & Approx. Sig. \\
\hline Pearson $\mathrm{R}$ & .577 & .031 & 17.327 & $.000^{\mathrm{c}}$ \\
\hline Spearman Correlation & .646 & .028 & 20.712 & $.000^{\mathrm{c}}$ \\
\hline $\mathrm{N}$ of Valid Cases & 602 & & & \\
\hline $\mathrm{R}=0.646$ & & & & \\
\hline $\mathrm{p}<0.001$ & & & & \\
\hline Statistically significant $(\mathrm{p}<0.001)$ & & & & \\
\hline
\end{tabular}

The direct ratio and average dependency shows that by increasing the DMF $(\mathrm{T}+\mathrm{t})$ index of the examined patients, there is an increase in the number of preventive restorations with composites and sealants. The descriptive analysis of the average distribution of the composite restorations placed by us for the purpose of treatment and according to the age of the examined patients is shown in Table 4. 
With the correlation analysis we establish a direct ratio dependency, which shows that with age increase, there is an increase in the number of preventive obstructions with composites $(\mathrm{r}=0.725 ; \mathrm{p}<0.001)$, Table 5. In Table 6 there is an inverse ratio showing that with age increase, there is a decrease in the glass ionomer cement (GIC) restorations ( $\mathrm{r}=-0.661 ; \mathrm{p}<0.001)$.

The inverse ratio dependency is showed in Table 7, which indicates that with increase of age, there is a decrease in the use of compomers for restorations in children above 12 years old $(r=-0.368 ; p<0.001)$.

The achieved direct ratio and dependency in Table 8, proves that with caries index increase DMF $(\mathrm{T}+\mathrm{t})$ of the examined patients, there is an increase of the number of preventive obstructions, made with composite and applying a sealant on the intact pits and fissures $(r=0.374 ; p<0.001)$.

Table 4. Descriptive analysis of the average distribution of placed composite restorations according to age of the examined patients

\begin{tabular}{|c|c|c|c|c|c|c|c|c|}
\hline \multicolumn{9}{|c|}{$\begin{array}{l}\text { Descriptives } \\
\text { Composites }\end{array}$} \\
\hline Age & $\mathrm{n}$ & Mean & Std. deviation & Std. error & $\begin{array}{l}95 \% \text { Confidence } \\
\text { Lower bound }\end{array}$ & $\begin{array}{l}\text { terval for mean } \\
\text { Upper bound }\end{array}$ & Minimum & Maximum \\
\hline 3.00 & 30 & .0000 & .00000 & .00000 & .0000 & .0000 & .00 & .00 \\
\hline 4.00 & 38 & .0263 & .16222 & .02632 & -.0270 & .0796 & .00 & 1.00 \\
\hline 5.00 & 75 & .0267 & .16219 & .01873 & -.0107 & .0640 & .00 & 1.00 \\
\hline 6.00 & 90 & .1222 & .39171 & .04129 & .0402 & .2043 & .00 & 2.00 \\
\hline 7.00 & 39 & .6154 & 1.06661 & .17079 & .2696 & .9611 & .00 & 4.00 \\
\hline 8.00 & 30 & .6000 & 1.06997 & .19535 & .2005 & .9995 & .00 & 4.00 \\
\hline 9.00 & 30 & .9667 & 1.44993 & .26472 & .4253 & 1.5081 & .00 & 4.00 \\
\hline 10.00 & 30 & 1.6667 & 1.51620 & .27682 & 1.1005 & 2.2328 & .00 & 5.00 \\
\hline 11.00 & 30 & 1.7000 & 1.46570 & .26760 & 1.1527 & 2.2473 & .00 & 5.00 \\
\hline 12.00 & 30 & 2.1667 & 1.34121 & .24487 & 1.6658 & 2.6675 & .00 & 5.00 \\
\hline 13.00 & 30 & 2.9667 & 2.31164 & .42205 & 2.1035 & 3.8298 & .00 & 9.00 \\
\hline 14.00 & 30 & 2.6667 & 2.59088 & .47303 & 1.6992 & 3.6341 & .00 & 12.00 \\
\hline 15.00 & 31 & 2.9032 & 1.59906 & .28720 & 2.3167 & 3.4898 & .00 & 6.00 \\
\hline 16.00 & 29 & 3.7241 & 3.25024 & .60355 & 2.4878 & 4.9605 & .00 & 11.00 \\
\hline 17.00 & 30 & 3.8667 & 2.94470 & .53763 & 2.7671 & 4.9662 & .00 & 11.00 \\
\hline 18.00 & 30 & 4.4000 & 3.03542 & .55419 & 3.2666 & 5.5334 & .00 & 12.00 \\
\hline Total & 602 & 1.4385 & 2.18383 & .08901 & 1.2637 & 1.6133 & .00 & 12.00 \\
\hline
\end{tabular}

Table 5. Correlation dependency between the placed restorations with composites and the age of the examined children

\begin{tabular}{|c|c|c|c|c|c|c|c|c|}
\hline \multicolumn{9}{|c|}{$\begin{array}{l}\text { Descriptives } \\
\text { Composites }\end{array}$} \\
\hline Age & $\mathrm{n}$ & Mean & Std. deviation & Std. error & \multicolumn{2}{|c|}{$95 \%$ Confidence interval for mean } & Minimum & Maximum \\
\hline 3.00 & 30 & .0000 & .00000 & .00000 & .0000 & .0000 & .00 & .00 \\
\hline 4.00 & 38 & .0263 & .16222 & .02632 & -.0270 & .0796 & .00 & 1.00 \\
\hline 5.00 & 75 & .0267 & .16219 & .01873 & -.0107 & .0640 & .00 & 1.00 \\
\hline 8.00 & 30 & .6000 & 1.06997 & .19535 & .2005 & .9995 & .00 & 4.00 \\
\hline 9.00 & 30 & .9667 & 1.44993 & .26472 & .4253 & 1.5081 & .00 & 4.00 \\
\hline 10.00 & 30 & 1.6667 & 1.51620 & .27682 & 1.1005 & 2.2328 & .00 & 5.00 \\
\hline 11.00 & 30 & 1.7000 & 1.46570 & .26760 & 1.1527 & 2.2473 & .00 & 5.00 \\
\hline 12.00 & 30 & 2.1667 & 1.34121 & .24487 & 1.6658 & 2.6675 & .00 & 5.00 \\
\hline 13.00 & 30 & 2.9667 & 2.31164 & .42205 & 2.1035 & 3.8298 & .00 & 9.00 \\
\hline 18.00 & 30 & 4.4000 & 3.03542 & .55419 & 3.2666 & 5.5334 & .00 & 12.00 \\
\hline Total & 602 & 1.4385 & 2.18383 & .08901 & 1.2637 & 1.6133 & .00 & 12.00 \\
\hline
\end{tabular}

Table 6. Correlation dependency of Pearson between the restorations with GIC and the age of the examined patients

\begin{tabular}{|c|c|c|c|c|c|}
\hline \multicolumn{6}{|l|}{ Symmetric Measures } \\
\hline & & Value & Asymp. Std. error ${ }^{a}$ & Approx. $\mathrm{T}^{\mathrm{b}}$ & Approx. Sig. \\
\hline Interval by interval & Pearson R & -.568 & .019 & -16.891 & $.000^{\mathrm{c}}$ \\
\hline Ordinal by ordinal & Spearman correlation & -.661 & .021 & -21.569 & $.000^{\mathrm{c}}$ \\
\hline $\mathrm{N}$ of valid cases & & 602 & & & \\
\hline
\end{tabular}


Table 7. Correlation dependency of Pearson between compomers restorations and the age of the examined patients

\begin{tabular}{|c|c|c|c|c|c|}
\hline \multicolumn{6}{|l|}{ Symmetric Measures } \\
\hline & & Value & Asymp. Std. error ${ }^{a}$ & Approx. $\mathrm{T}^{\mathrm{b}}$ & Approx. Sig. \\
\hline Interval by interval & Pearson R & -.388 & .024 & -10.296 & $.000^{\mathrm{c}}$ \\
\hline Ordinal by ordinal & Spearman correlation & $\begin{array}{l}-.368 \\
602\end{array}$ & .033 & -9.694 & $.000^{\mathrm{c}}$ \\
\hline $\mathrm{N}$ of Valid Cases & & 602 & & & \\
\hline
\end{tabular}

Table 8. Relationship between filling with compomers and the caries index DMF $(\mathrm{T}+\mathrm{t})$ of the studied patients

\begin{tabular}{|c|c|c|c|c|c|}
\hline \multirow{2}{*}{ Model } & \multicolumn{3}{|c|}{ Unstandardized coefficients Standardized coefficients } & \multirow{2}{*}{$\mathrm{t}$} & \multirow{2}{*}{ Sig. } \\
\hline & $\mathrm{B}$ & Std. error & Beta & & \\
\hline (Constant) & 4.487 & .179 & & 25.029 & .000 \\
\hline${ }^{1}$ Composites & 678 & .069 & .374 & 9.878 & .000 \\
\hline
\end{tabular}

\subsection{Discussion}

Restorative treatment of dental caries does not stop the development of the carious process. This conclusion has long been known in modern pediatric dentistry. Part of the caries lesions does not progress and there is no need for their restoration. The new management of dental medicine and dental caries includes a caries risk assessment and understanding the pathology of the caries process. Suitable preventive methods and an individual control of the progression of the caries are necessary, completed with invasive and restorative therapy only when needed [38].

The information for the diagnostics of caries in primary teeth is scarce [39] and in this dentition there are different criteria depending on the thin layers of enamel and dentin and the wider interdental contacts [40]. The indications for restorative/obstructive/therapy are scarcely studied and the decisions depend on the assessment of the clinician [41]. In modern dental clinics there is still a need for making a decision when to restore a caries lesion, the clinical criteria for visual discovery of enamel cavitation, observation of the enamel and x-ray of the lesions [42]-[44].

The success and pros from the restorative treatment include: obstructing the cavity of the cavitated lesions after the preparation or defects in the enamel. It is necessary to stop the progression of the demineralization of areas of the enamel, which are caries non-resistant, restore the tooth structure's entirety and prevent the spreading of the infection towards the pulp, as well as prevent the migration of teeth as a result of tooth structure loss.

The potential risks of restorative method include a decrease in the function longevity of the teeth by making them more suspicious to fractures, recidive lesions, unsuccessful restoration or making a collision with the pulp while drilling, [45]-[47]. Primary teeth can be more prone to unsuccessful restoration. When obstructing primary teeth, the clinician needs to determine the remaining time that the tooth is going to spend in the oral cavity, before it exfoliates.

One of the main goals of the restorative treatment is limiting the demineralization from the caries, protecting and preventing the tooth structures and maintaining the vitality of the pulp, when possible. The American Academy of Pediatric Dentistry (AAPD) determines that the aim of treating carious teeth is to prevention the vitality of the pulp, especially for permanent teeth with underdeveloped roots. There are materials and methods for restoration of permanent teeth in Pediatric Dentistry [48]. The facts from two random control studies show that no preparation can stop the development of the tooth caries for as long as preventing the tooth and cavity by sealing with a definitive restoration [49], [50].

\section{CONCLUSION}

The average frequency of caries lesions shows their high distribution among the examined patients. The correlation analysis determined that with increasing age of the patients the number and frequency of composite restorations and sealants in the control groups increased. The direct ratio and average dependency shows that by increasing the DMF $(\mathrm{T}+\mathrm{t})$ index of the examined patients, there is an increase in the number of preventive fillings with composites and sealants. In all tests and analyses there is a statistically significant difference. 


\section{ACKNOWLEDGEMENTS}

This research is funded by the authors and their working institutions. The authors express their gratitude to Biostatistics Mrs. Valentina Velikova for the help and assistance for visualizing the work with tables and figures.

\section{REFERENCES}

[1] Damyanova, Dobrinka, Radosveta, and Andreeva-Borisova, "A retrospective study of dental caries prevalence in 3-6 years old children," International Journal of Scientific and Research Publications, vol. 10, no. 4, pp. 32-40, 2020, doi: 10.29322/IJSRP.10.04.2020.p10004.

[2] Laske M, Opdam Niek J.M, and Bronkhorst E.M, et al., "Minimally invasive intervention for primary caries lesions: are dentists implementing this concept?," Caries Research. vol. 53, no. 5, pp. 204-216, 2019.

[3] The Reference Manual of Pediatric Dentistry, "Pediatric restorative dentistry," pp. 340-352., 2019. [Online]. Available: www.aapd.org/research/oral-health-policies--recommendations/pediatric-restorative-dentistry/

[4] Weyant RJ et al., "Topical fluoride for caries prevention: Executive summary of the updated recommendations and supporting systematic review," Journal American Dental Association, vol. 144, no.11, pp. 1279-91. 2013.

[5] Mojtaba, Dorri et al., "Atraumatic restorative treatment versus conventional restorative treatment for managing dental caries," Cochrane Database of Systematic Reviews, vol. 12, no. 1, pp. 1-68, 2017. doi: 10.1002/14651858.CD008072.pub2.

[6] Frencken, Jo E, Holmgren, and Chr. J, "Caries management through the Atraumatic Restorative Treatment (ART) approach and glass-ionomers: update 2013," Brazilian Oral Research, vol. 28, no. 1 São Paulo, 2014, doi: https://doi.org/10.1590/S1806-83242013000600001.

[7] Raggio DP., Hesse D, Lenzi TL, Guglielmi CAB, and Braga MM., "Is atraumatic restorative treatment an option for restoring occluso-proximal caries lesions in primary teeth? A systematic review and meta-analysis," International Journal Paediatric Dental, vol. 23, no. 6, pp. 435-43, 2013

[8] Park, E. Yo, and Kang, S., "Current aspects and prospects of glass ionomer cements for clinical dentistry," Yeungnam University Journal of Medicine, vol. 37, no. 3, pp. 169-178, 2020, doi: https://doi.org/10.12701/yujm.2020.00374.

[9] Vibeke, Qvist et al., "Fluorides leaching from restorative materials and the effect on adjacent teeth," International Dental Journal, vol. 60, no. 3, pp. 156-160, 2010

[10] Daou MH., Attin T, Göhring TN., "Clinical success of compomer and amalgam restorations in primary molars: Follow up in 36 months," Schweiz Monatsschr Zahnmed, vol. 119, no. 11, pp. 1082-8, 2009.

[11] Welbury RR., Shaw AJ, Murray JJ, Gordon PH, McCabe JF., "Clinical evaluation of paired compomer and glass ionomer restorations in primary molars: Final results after 42 months," British Dental Journal, vol. 189, no. 2, pp. 93-7, 2000

[12] Damyanova D.M., "Severe Early Childhood Caries - A Clinical Case Report," Archives of Dentistry and Oral Health, vol. 2, no. 1, pp. 12-18, 2019.

[13] Pires, C. W et al., "Is there a best conventional material for restoring posterior primary teeth? A network metaanalysis," Brazilian Oral Research, vol. 32 São Paulo 2018, doi: 10.1590/1807-3107bor-2018.vol32.0010.

[14] Paryab, M et al., "Fracture strength of severely damaged primary anterior teeth after restoration with composite resin and resin-modified glass ionomer cement,” Journal Islamic Dental Association Iran, vol. 28, no. 2, pp. 57-63, 2016, doi: 10.30699/jidai.29.2.57.

[15] Dimitrova D, Andreeva R, and Dimova-Gabrovska M., "Application of aesthetic crowns in children patients," Varna Medical Forum, vol. 7, pp. 173-177, 2018

[16] Dimitrova, D, "Study of patient satisfaction with prosthetic treatment," Journal of Medical and Dental Practice, vol. 5, no. 3, pp. 914-919, 2018, doi: 10.18044/Medinform.201853.914.

[17] Dimova, M, "Registration of centric occlusion in patients with bruxism and bruxomania through articulating paper and the system t-scan - comparative analysis," Journal of IMAB - Annual Proceeding (Scientific Papers), vol. 20, no. 1, pp. 520-526, 2014, doi: 10.5272/jimab.2014201.520.

[18] Donly K.J, "Restorative dentistry for children," Dental Clinics North America, vol. 57, no. 1, pp. 75-82, 2013, doi: 10.1016/j.cden.2012.09.001.

[19] Walia, T et al., "A randomised controlled trial of three aesthetic full-coronal restorations in primary maxillary teeth," European Journal of Paediatric Dentistry, vol. 15, no. 2, pp. 113-8, 2014.

[20] Alaki, S. M et al., "Comparing zirconia to anterior strip crowns in primary anterior teeth in children: a randomized clinical trial," BMC Oral Health, vol. 20, no 313, 2020, doi: 10.1186/s12903-020-01305-1

[21] Dermata, A et al., "Comparison of resin modified glass ionomer cement and composite resin in class II primary molar restorations: a 2-year parallel randomised clinical trial," European Archives of Paediatric Dentisry, vol. 19, pp. 393-401, 2018, doi: 10.1007/s40368-018-0371-7.

[22] Heintze SD and Rousson V., "Clinical effectiveness of direct Class II restorations - A meta-analysis," Journal Adhesive Dentistry; vol. 14, no. 5, pp. 407-31, 2012, doi: 10.3290/j.jad.a28390.

[23] Chisini, L.A et al., "Restorations in primary teeth: A systematic review on survival and reasons for failures". International Journal of Paediatric Dentistry, vol. 28, no. 2, pp. 123-139, 2018, doi: 10.1111/ipd.12346.

[24] Restorative Consensus and Articles Foundational 2021. [Online]. Available: https://iapdworld.org/wpcontent/uploads/2020/12/11_Restorative-Dentistry-in-Children.pdf. 
[25] Françoise, H van de Sande, "Patient risk factors' influence on survival of posterior composites," Journal of Dental Research, vol. 92, no. S7, pp. 78S-83S, 2013, doi: 10.1177/0022034513484337.

[26] Alves dos Santos MP., Luiz RR, and Maia LC., "Randomised trial of resin-based restorations in Class I and Class II beveled preparations in primary molars: 48-month results," Journal Dentistry, vol. 8, no. 6, pp. 451-9, 2010, doi: 10.1016/j.jdent.2010.02.004.

[27] Bücher, K et al., "Survival characteristics of composite restorations in primary teeth," Clinical Oral Investigations, vol. 19, no. 7, pp. 1653-1662, 2015, doi: 10.1007/s00784-014-1389-9.

[28] Vignesh, K.C, Eswar, Kandaswamy, and Muthu, M.S., "A comparative evaluation of fracture toughness of composite resin vs protemp 4 for use in strip crowns: An in vitro study," International Journal of Clinical Pediatric Dentistry, vol. 13, no. 1, pp. 57-60, 2020, doi: 10.5005/jp-journals-10005-1711.

[29] Damyanova, D, "The knowledge of dentists for the prevention of influence of the caries process," International Journal of Public Health Science (IJPHS), vol. 9, no. 3, pp. 176-183. 2020, doi: http://doi.org/10.11591/ijphs.v9i3.20478

[30] Ahovuo-Saloranta, A et al., "Pit and fissure sealants for preventing dental decay in permanent teeth," Cochrane Database Systematic Reviews, vol. 7, no. 7, pp. 1-143, 2017, doi: 10.1002/14651858.CD001830.pub5.

[31] Frencken, Jo. E, "Atraumatic restorative treatment and minimal intervention dentistry," British Dental Journal, vol. 223, no. 3, pp. 183-189, 2017, doi: 10.1038/sj.bdj.2017.664.

[32] Al-Sultani, Hassan Faleeh Farhan, et al., "Clinical Evaluation of pit and fissure sealants placed by undergraduate dental students in 5-15 years-old children in Iraq," Pesquisa Brasileira em Odontopediatria e Clínica Integrada, vol. 20 João Pessoa 2020, doi: https://doi.org/10.1590/pboci.2020.004

[33] Yoshishige, Yamada, Yuichi, and Kimura, "Reconsideration of invasive technique for occlusal fissure before fissure sealant," Interventions in Pediatric Dentistry Open Access Journal, vol. 4, no. 3, pp. 324-329, 2020, doi: 10.32474/IPDOAJ.2020.04.000187.

[34] Santiago, J., David, E, "The use of two media of instruction in biology: A quasi-experimental study," International Journal of Advanced Engineering, Management and Science (IJAEMS), vol. 5, no. 2, pp. 111-115, 2019.

[35] Turton, B et al. "Epidemiological survey of early childhood caries in Cambodia". BMC Oral Health, vol. 19, no. 107, pp. 1-7, 2019, doi: https://doi.org/10.1186/s12903-019-0800-y.

[36] Tracy, Sharon et al., "Topical fluoride for caries prevention: Executive summary of the updated clinical recommendations and supporting systematic review, "Journal of the American Dental Association (1939), vol. 144, no. 11, pp. 1279-91, 2013, doi: 10.14219/jada.archive.2013.0057.

[37] Damyanova Dobrinka, Elitsa, Sabeva, Mariya, and Miteva-Hristova, "Treatment after illness of early childhood caries - clinical case report," Quest Journals Journal of Medical and Dental Science Research, vol. 4, no. 5, pp. 7982, 2017.

[38] American Academy of Pediatric Dentistry, "Pediatric restorative dentistry. The Reference Manual of Pediatric Dentistry. Chicago, Ill: American Academy of Pediatric Dentistry, pp. 371-83, 2020. [Online]. Available: https://www.aapd.org/globalassets/media/policies_guidelines/bp_restorativedent.pdf?v=new

[39] Cummins, D, "The development and validation of a new technology, based upon $1.5 \%$ arginine, an insoluble calcium compound and fluoride, for everyday use in the prevention and treatment of dental caries." Journal of dentistry, vol. 41, no. S2, pp. s1-s11, 2013, doi: https://doi.org/10.1016/j.jdent.2010.04.002

[40] Nelson SJ, "Wheeler's dental anatomy, physiology, and occlusion," 9th ed. Philadelphia, Pa.: WB Saunders; 2010.

[41] Ghoneim A et al., "What influences the clinical decision-making of dentists? A cross-sectional study," PLoS ONE, vol. 15, no. 6, pp. 1-11, 2020, doi: https://doi.org/10.1371/journal.pone.0233652

[42] American Academy of Pediatric Dentistry, "Guideline on caries risk assessment and management for infants, children, and adolescents," Pediatric Dentistry, vol. 38, no. 6, (special issue), pp. 142-149, 2014.

[43] Ismail A.I et al., "The international caries detection and assessment system (ICDAS): An integrated system for measuring dental caries," Community Dentistry Oral Epidemiology, vol. 35, no. 3, pp. 170-8, 2007, doi: 10.1111/j.1600-0528.2007.00347.x.

[44] Beauchamp J et al., "Evidence-based clinical recommendations for the use of pit-and-fissure sealants: A report of the American dental association council on scientific affairs," Journal American Dental Association, vol. 139, no. 3, pp. 257-68, 2008, doi: 10.14219/jada.archive.2008.0155.

[45] Jamali, Z et al., "Does the length of dental treatment influence children's behaviour during and after treatment? A systematic review and critical appraisal," Dental Research Dental Clinics Dental Prospects, vol. 12, no. 1, pp. 6876, 2018, doi: 10.15171/joddd.2018.011

[46] Saleha, Shah et al., "Paediatric dentistry- novel evolvement," Annals of Medicine and Surgery, vol. 25, pp. 21-29, 2018, doi: https://doi.org/10.1177/0022034515571184

[47] Innes, N.P et al., "The FiCTION dental trial protocol - filling children's teeth: indicated or not?," BMC Oral Health, vol. 13, no. 25, pp. 1-13, 2013, doi: https://doi.org/10.1186/1472-6831-13-2

[48] Peev, St, Sabeva, El, "Bone block augmentation - a long-term follow-up," Scripta Scientifica Medicinae Dentalis, vol. 4, No. 2, pp. 29-35, 2018.

[49] Innes NP., Evans DJ, and Stirrups DR., "Sealing caries in pri- mary molars: Randomized control trial, 5-year results," Journal Dental Research, vol. 90, No. 12, pp. 1405-10, 2011, doi: 10.1177/0022034511422064.

[50] Schwendicke F et al., "Treating pit-and-fissure caries: A systematic review and network meta-analysis," Journal of Dental Research, vol. 94, no. 4, pp. 522-33, 2015, https://doi.org/10.1177/0022034515571184. 